\title{
Hemorrhagic Bullous Lesions in the Oral Cavity
}

\author{
Ajay Chauhan ${ }^{1}$ Ankur Guliani² \\ ${ }^{1}$ Department of Internal Medicine, Civil Hospital, Baddi, \\ Himachal Pradesh, India \\ ${ }^{2}$ Department of Dermatology, Venereology and Leprology, \\ Civil Hospital, Baddi, Himachal Pradesh, India
}

Ann Natl Acad Med Sci (India):2020;56:234-234

A 55-year-old female presented with an asymptomatic, bloodfilled blister inside the oral cavity for last 2 days. There was no history of trauma, oral/dental surgery, and intake of hot and crispy foods. On examination, a single, well-defined, nontender hemorrhagic bulla of size $2 \mathrm{~cm}$ in diameter was observed over the lateral surface of the tongue ( - Fig. 1). Bulla ruptured spontaneously and healed within 5 to 6 days without any scarring. Rest of the mucocutaneous examination was normal. Here, oral cavity and teeth were normal and healthy. She was a known case of hypertension, but not taking regular medication. Her blood pressure was $170 / 120 \mathrm{~mm}$ of $\mathrm{Hg}$ at the time of visit. Complete blood counts and hepatic and renal function tests were normal. Her prothrombin time (PT/international normalized ratio) and activated partial thromboplastin time (aPTT) were within normal limits. Her fasting blood sugar level was $118 \mathrm{mg} / \mathrm{dL}$ and $\mathrm{HbA} 1 \mathrm{C}$ was $6.2 \%$.

On the basis of classical clinical morphology and investigations, we reached the diagnosis of angina bullosa hemorrhagica (ABH).

$\mathrm{ABH}$ is characterized by the sudden and spontaneous appearance of generally single, painless hemorrhagic blisters on oral mucosa not attributable to blood dyscrasias. ${ }^{1}$ The diameters of lesion may range from 2 to $3 \mathrm{~cm}$ that commonly involves soft palate; however, other sites may be involved including buccal mucosa, lips, tongue border, epiglottis, and esophagus. ${ }^{1,2}$ Clinically, the blisters start as dark red to purple, painless or rarely painful blisters that usually rupture, releasing blood mixed fluid, and leaving an eroded surface that heals without any treatment within 7 to 10 days. $^{2}$

The etiology of $\mathrm{ABH}$ is uncertain. However, many predisposing factors have been identified; systemic diseases such as diabetes mellitus, hypertension and chronic renal failure, and local causes such as trauma, hot and spicy foods, dental procedures, and steroid inhalers. ${ }^{3}$ Common differentials of $\mathrm{ABH}$ include bullous lichen planus, bullous pemphigoid, thrombocytopenia, and epidermolysis bullosa. The diagnosis
Address for correspondence Ankur Guliani, MD, Department of Dermatology, Venereology and Leprology, Civil Hospital, Baddi, Solan, Himachal Pradesh 173205, India (e-mail: gulianiankur502@gmail.com).

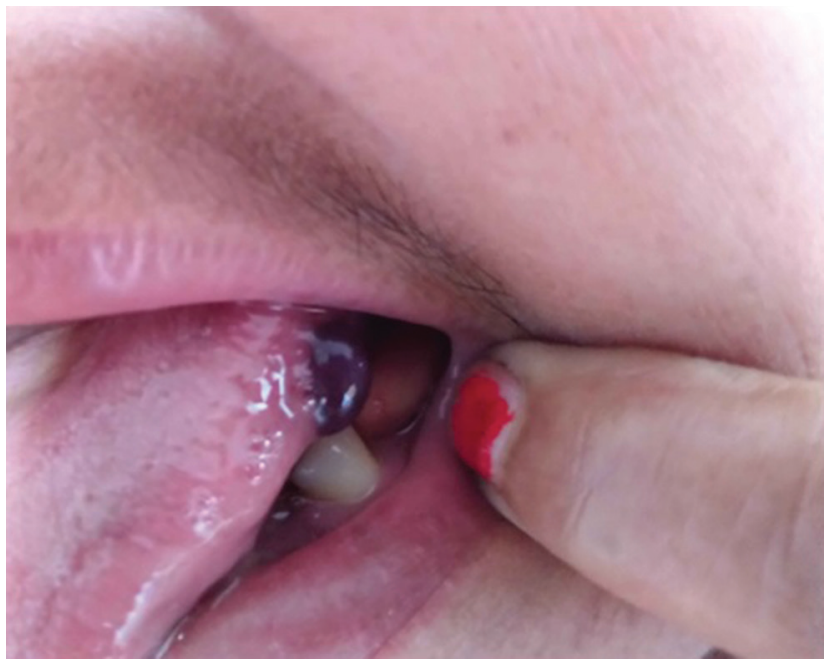

Fig. 1 Single, well-defined hemorrhagic bulla of size $2 \mathrm{~cm}$ in diameter over the left side of lateral surface of the tongue.

of $\mathrm{ABH}$ is mainly clinical and histopathology is not required. However, it is important to look for and treat the predisposing factors associated and differentiate it from other severe chronic disorders of the oral cavity to avoid unnecessary medications.

\section{Conflict of Interest}

None declared.

\section{References}

1 Supekar BB, Sawatkar G, Wankhade VH. Angina bullosa hemorrhagica. Indian Dermatol Online J 2019;10(1):89

2 Singh D, Misra N, Agrawal S, Misra P. Angina bullosa haemorrhagica. BMJ Case Rep 2013;2013:bcr2012008505

3 Horie N, Kawano R, Inaba J, et al. Angina bullosa hemorrhagica of the soft palate: a clinical study of 16 cases. J Oral Sci 2008;50(1):33-36
DOI https://doi.org/ 10.1055/s-0040-1713011 ISSN 0379-038X. (c) 2020. National Academy of Medical Sciences (India).

This is an open access article published by Thieme under the terms of the Creative Commons Attribution-NonDerivative-NonCommercial-License, permitting copying and reproduction so long as the original work is given appropriate credit. Contents may not be used for commercial purposes, or adapted, remixed, transformed or built upon. (https://creativecommons.org/licenses/by-nc-nd/4.0/).

Thieme Medical and Scientific Publishers Pvt. Ltd. A-12, 2nd Floor, Sector 2, Noida-201301 UP, India 